This is an author produced version of a paper published in Journal of Hydrology. This paper has been peer-reviewed and is proof-corrected, but does not include the journal pagination.

Citation for the published paper:

Essou, G., Arsenault, R. and Brissette, F. (2016). Comparison of climate datasets for lumped hydrological modeling over the continental United States. Journal of Hydrology, 537, 334-345. doi: 10.1016/j.jhydrol.2016.03.063

Published version can be viewed here:

http://dx.doi.org/10.1016/j.jhydrol.2016.03.063

(C) 2016. This manuscript version is made available under the CC-BY-NC-ND

4.0 license http://creativecommons.org/licenses/by-nc-nd/4.0/ 


\section{Comparison of climate datasets for lumped hydrological modeling over the continental United States}

Gilles R. C. ESSOU a, Richard ARSENAULT b, François P. BRISSETTE c

a Corresponding author: (Graduate student), École de technologie supérieure, 1100 rue Notre-Dame Ouest, Montréal QC, H3C 1K3, Canada, Email: essougilles@yahoo.fr / gilles.essou.1@ens.etsmtl.ca

b Graduate student, École de technologie supérieure, 1100 rue Notre-Dame Ouest, Montréal QC, H3C 1K3, Canada,

Email: richard.arsenault.1@ens.etsmtl.ca

c Professor, École de technologie supérieure, 1100 rue Notre-Dame Ouest, Montréal QC, H3C 1K3, Canada, Email: francois.brissette@etsmtl.ca 


\begin{abstract}
Climate data measured by weather stations are crucially important and regularly used in hydrologic modeling. However, they are not always available due to the low spatial density and short record history of many station networks. To overcome these limitations, gridded datasets have become increasingly available. They have excellent continuous spatial coverage and no missing data. However, these datasets are usually interpolated using station data, with little new information besides elevation. Furthermore, minimal validation has been done on most of these datasets. This study compares three such datasets covering the continental United States to evaluate their differences and their impact on lumped hydrological modeling. Three daily time step gridded datasets with resolutions varying between $0.25^{\circ}$ and $1 \mathrm{~km}$ were used in this study - Santa-Clara, Daymet and CPC. The hydrological modeling evaluation of these datasets was performed over 424 basins from the MOPEX database. Results show that there are significant differences between the datasets, even though they were essentially all interpolated from almost the same climate databases.
\end{abstract}

Despite those differences, the hydrological model used in this study was able to perform equally well after a specific calibration to each dataset. While there were a few exceptions, by and large, Nash-Sutcliffe efficiency metrics obtained in validation were not statistically different from one database to the other for most basins. It appears that there are no 
reasons to favor one dataset versus another for lumped hydrological modeling, and that these datasets perform just as well as using the original station data.

Keywords: Interpolated data, bias, hydrological modeling, calibration, performance comparison.

\section{Introduction}

Climate data obtained from ground weather stations are the main inputs to hydrological models. However, spatial coverage of weather stations is often limited in mountain areas and low-population areas. In addition, short temporal coverage and missing data are typical of many station records.

To overcome these problems, many water management agencies have been using gridded datasets obtained by interpolating station data onto a regular grid. Such datasets have continuous spatial and temporal coverage and are much simpler to use than their station dataset counterparts. Several competing interpolation methods have been proposed. The simplest interpolate between stations (i.e. Thiessen polygons, simple kriging) (Hartkamp et al. 1999; Skaugen and Andersen 2010), whereas the more complex use additional information from other sources or integrate physical properties such as the atmospheric lapse 
rate. This is the case for local (Daly et al. 1994; Hasenauer et al. 2003; Taylor et al. 1997; Thornton et al. 1997) and regional regression methods (Chen et al. 2007; Mahdian et al. 2009; Perry and Hollis 2005). On the other hand, even though gridded datasets offer good spatial coverage, their reliability may be questionable in areas with a sparse weather station network (Mizukami and Smith 2012). Gridded datasets also contain uncertainties linked to each specific interpolation scheme (Tozer et al. 2012).

In the United-States (as in many other countries throughout the world) there has been a widespread effort to produce robust interpolated datasets. Several such datasets have been made freely available to the scientific community by several groups such as the University of SantaClara (Maurer et al. 2002), the Climate Prediction Center (CPC) (Higgins et al. 2000), and Daymet (Thornton et al. 2012; Thornton et al. 1997). These databases have been used in various recent hydrological studies (Ali et al. 2014; Elsner et al. 2014; Gallo and Xian 2014; McEvoy et al. 2014; Neiman et al. 2014; Singh et al. 2014; Ye et al. 2014; Zurita-Milla et al. 2014). However, to date, there exists little validation work as to the ability of these datasets for hydrological studies. Accordingly, the present study aims at comparing various precipitation and temperature gridded datasets at the basin scale, and to evaluate the differences for lumped hydrological modeling. 


\section{Study area and datasets}

\subsection{Study area}

The study area is a group of 424 catchments in the continental UnitedStates, within boundaries reaching from $67^{\circ} \mathrm{W}$ to $125^{\circ} \mathrm{W}$ longitude and $25^{\circ} \mathrm{N}$ to $50^{\circ} \mathrm{N}$, as shown in Fig. 1.

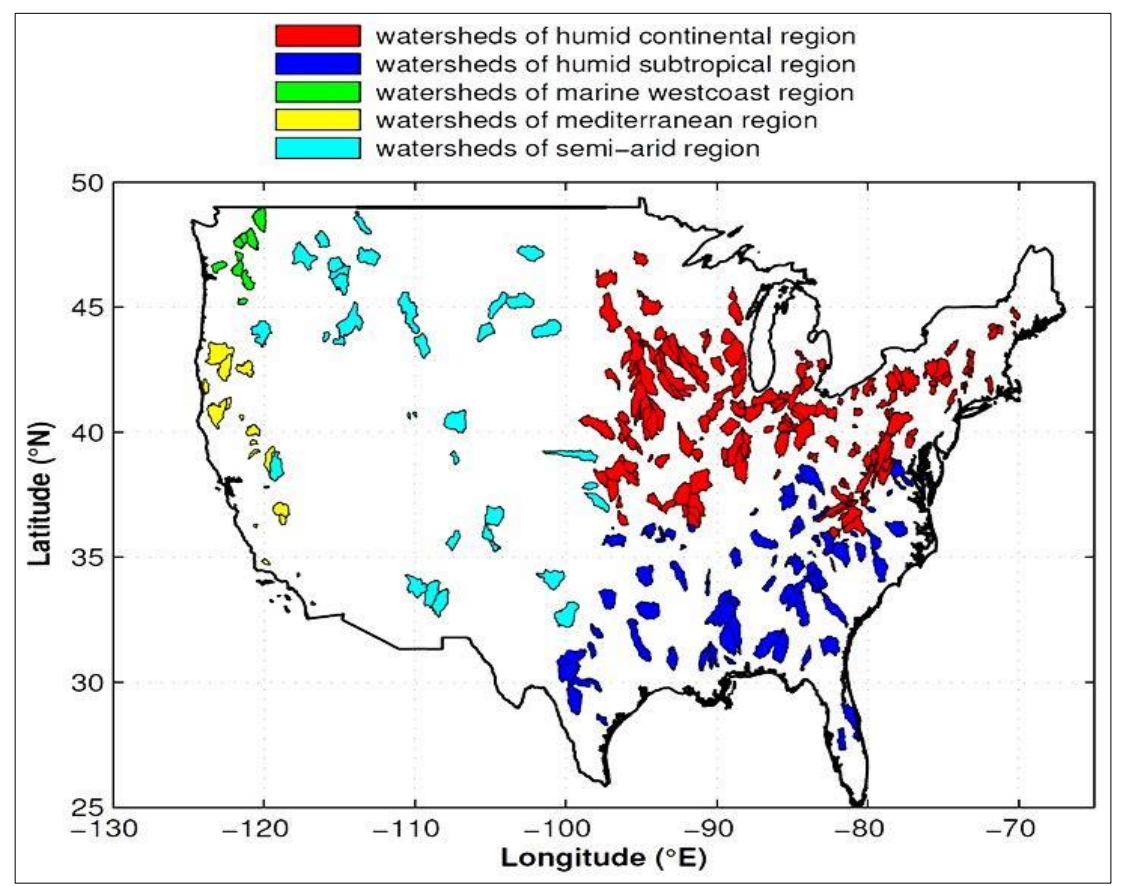

FIG. 1. Location and climate classification of the 424 catchments used in this study.

The catchments are dispersed in 5 climatic zones according to the Köppen-Geiger classification system (Kottek et al. 2006). There are 236 basins classified as humid continental, 107 as humid subtropical, 13 in the marine west-coast region, 24 as Mediterranean and 44 as semi-arid. The catchments range between $66 \mathrm{~km}^{2}$ and $10325 \mathrm{~km}^{2}$ in size. 


\subsection{Datasets}

All the comparisons and simulations were performed with daily climate data as well as daily discharge time series. The four databases used in this study are as follow:

\subsubsection{MOPEX area averaged data}

The MOdel Parameter Estimation eXperiment (MOPEX) database contains precipitation, temperature (minimum and maximum) and streamflows on a daily time step. The database covers the years 1949-2003. Its conception stems from the National Climatic Data Center (NCDC) weather station observations (about 16,139 stations) (Duan et al. 2006). In fact, the MOPEX climate data are averaged observation values on the different catchments. An inverse distance weighting method was implemented to estimate the final MOPEX climate data. A detailed description of this data source is available in Schaake et al. (2006). It is important to note that each catchment in the database requires a minimal density of weather stations, which is determined by the size of the catchment as explained in Schaake et al. (2000). Furthermore, only time series of length greater than 10 years were admitted in the database. The reference streamflow data is also taken from this database. The MOPEX dataset is available online: ftp://hydrology.nws.noaa.gov/pub/gcip/mopex/US_Data 


\subsubsection{Santa-Clara gridded data}

The University of Santa-Clara gridded dataset were initially developed in Washington, but they were formatted into their current form at the University of Santa-Clara. The daily precipitation and temperatures (minimum and maximum) are available for the years 1949-2003. They were interpolated on a $0.125^{\circ} \mathrm{x} 0.125^{\circ}$ grid using the weather measurement data provided by the National Oceanic and Atmospheric Administration (NOAA) cooperative network, averaging 1 station per 700 $\mathrm{km}^{2}$ (Maurer et al. 2002). The interpolation algorithm is based on the Synergraphic Mapping System (SYMAP) by Shepard (1984) and implemented as proposed by Widmann and Bretherton (2000). Particularly, the precipitations were downscaled to correspond to the long-term means of the precipitations from the Parameter-elevation Regressions on Independent Slopes Model (PRISM) (Daly et al. 1994; Daly et al. 1997). More precisely, it relies on 12 monthly means for the 19611990 period, which are statistically adjusted to capture the local variations on complex terrain. The Santa-Clara dataset is available online: http://hydro.engr.scu.edu/files/gridded_obs/daily/ncfiles_2010

\subsubsection{Climate Prediction Center gridded data}

The Climate Prediction Center (CPC) data contains precipitation data only for the years $1949-2003$ with a spatial resolution of $0.25^{\circ} \times 0.25^{\circ}$. The interpolation uses three main sources of observation data (Higgins et al. 
2000). The first is the CPC cooperative network stations for the 19961999 period (15622 stations). The second is daily observations from the NCDC for the years 1948-1998 (approximately 16139 stations). The third is from the Hourly Precipitation Dataset (HPD) (approximately 5933 stations) (Higgins et al. 1996). The interpolation uses the Cressman method (Cressman 1959). Information on the location of weather stations used to build the CPC data can be found at: http://www.cpc.ncep.noaa.gov/products/Precip_Monitoring/Figures/NA MS/NAMS_curr.p.gnum.gif. The CPC dataset is available online: http://www.esrl.noaa.gov/psd/data/gridded/data.unified.daily.conus.ht $\underline{\mathrm{ml}}$

\subsubsection{Daymet gridded data}

The Daymet dataset includes maximum and minimum temperatures and precipitation on a daily scale for the period 1980-2003. They were produced using the Daymet suite, an ensemble of algorithms and software designed to interpolate and extrapolate values at grid points with a $1 \mathrm{~km} \times 1 \mathrm{~km}$ resolution (Thornton et al. 2012). Daymet uses observation network data to perform the interpolation with a Gaussian weighting scheme. A detailed description of Daymet is available in (Thornton et al. 1997). Information on the location of weather stations used to build the Daymet data can be found at: 
https://daymet.ornl.gov/overview.html. The Daymet dataset is available online: http://daymet.ornl.gov/.

A summary of the dataset characteristics is presented in Table 1.

TABLE 1. Characteristics of datasets used in this study

\begin{tabular}{|c|c|c|c|c|c|c|}
\hline Dataset & $\begin{array}{l}\text { Spatial } \\
\text { resolution }\end{array}$ & $\begin{array}{l}\text { Temporal } \\
\text { domain }\end{array}$ & Variables & $\begin{array}{l}\text { Interpolati } \\
\quad \text { on } \\
\text { algorithm/ } \\
\text { technique }\end{array}$ & Source & Reference \\
\hline MOPEX & --- & $\begin{array}{l}1949- \\
2003\end{array}$ & $\begin{array}{l}\mathrm{P}, \text { Tmin, } \\
\text { Tmax, } \\
\mathrm{PE}, \mathrm{Q}\end{array}$ & $\begin{array}{l}\text { Inverse } \\
\text { distance }\end{array}$ & $\begin{array}{c}\text { ftp://hydrology.n } \\
\text { ws.noaa.gov/pub } \\
\text { /gcip/mopex/US_ } \\
\text { Data }\end{array}$ & $\begin{array}{c}\text { (Duan et al. } \\
\text { 2006) }\end{array}$ \\
\hline Santa-Clara & $\begin{array}{c}0.125^{\circ} \mathrm{x} \\
0.125^{\circ}\end{array}$ & $\begin{array}{l}1949- \\
2010\end{array}$ & $\begin{array}{l}\mathrm{P}, \text { Tmin, } \\
\text { Tmax, } \\
\mathrm{W}\end{array}$ & $\begin{array}{l}\text { synergrap } \\
\text { hic } \\
\text { mapping } \\
\text { system } \\
\text { (SYMAP) }\end{array}$ & $\begin{array}{l}\text { http://hydro.engr } \\
\text {.scu.edu/files/gri } \\
\text { dded_obs/daily/n } \\
\text { cfiles_2010 }\end{array}$ & $\begin{array}{c}\text { (Maurer et al. } \\
\text { 2002) }\end{array}$ \\
\hline CPC & $\begin{array}{l}0.25^{\circ} \mathrm{x} \\
0.25^{\circ}\end{array}$ & $\begin{array}{l}1949- \\
2013\end{array}$ & $\mathrm{P}$ & $\begin{array}{l}\text { Optimal } \\
\text { interpolat } \\
\text { ion (OI) }\end{array}$ & $\begin{array}{l}\text { http://www.esrl.n } \\
\text { oaa.gov/psd/data } \\
\text { /gridded/data.uni } \\
\text { fied.daily.conus.h } \\
\text { tml }\end{array}$ & $\begin{array}{c}\text { (Higgins et al. } \\
\text { 2000) }\end{array}$ \\
\hline Daymet & $1 \mathrm{~km} \times 1 \mathrm{~km}$ & $\begin{array}{l}1980- \\
2013\end{array}$ & $\begin{array}{l}\text { P, Tmin, } \\
\text { Tmax, } \\
\text { Srad, } \\
\text { Vp, Swe }\end{array}$ & --- & $\begin{array}{c}\text { http:// daymet.or } \\
\text { nl.gov/ }\end{array}$ & $\begin{array}{l}\text { (Thornton et } \\
\text { al. 2012; } \\
\text { Thornton et } \\
\text { al. 1997) }\end{array}$ \\
\hline
\end{tabular}

$\mathrm{P}=$ Precipitation, $\quad$ Tmin $=$ minimum temperature; $\quad$ Tmax $=$ maximum temperature; $\mathrm{PE}=$ potential evaporation, $\mathrm{Q}=$ streamflow; $\mathrm{W}=$ wind speed; Srad=shortwave radiation; $\mathrm{V} p=$ vapor pressure; Swe=snow-water equivalent. 


\section{Methodology}

\subsection{Dataset comparison}

The interpolated data grid points inside each of the catchments were averaged using the inverse distance weighting method calculated with respect to the catchment centroid (Dirks et al. 1998). This method was shown to be amongst the best interpolation methods for such uses (Baillargeon et al. 2004; Ruelland et al. 2008). The comparison was performed on the daily, seasonal and extreme data. Moreover, the daily data was compared by climatic zone.

The first comparison criterion used in this study is the well-known Root Mean Squared Error (RMSE), which is defined as:

$$
R M S E=\sqrt{\frac{1}{N} \sum_{i=1}^{N}\left(X_{i}-Y_{i}\right)^{2}}
$$

where $\mathbf{X}_{\mathbf{i}}$ and $\mathbf{Y}_{\mathbf{i}}$ represent data values for day i, from $\mathrm{X}$ and $\mathrm{Y}$ datasets, and $\mathrm{N}$ is the length of the time series.

The RMSE gives an indication on the difference amplitude between two series. An RMSE value of 0 is a perfect fit, and larger values indicate larger errors.

The second comparison criterion is the bias $(\boldsymbol{B})$, defined as:

$$
B=\frac{1}{N} \sum_{i=1}^{N}\left(X_{i}-Y_{i}\right)
$$


The bias allows estimating how much one series underestimates or overestimates a second series. A bias of 0 indicates a perfect fit. A positive bias indicates an overestimation of the observations, while the opposite is true for negative biases.

For temperature, biases were directly computed between each of the datasets. For precipitation, since the number of datasets is higher, biases were computed against a reference value equal to the average value of the 4 datasets in the studies. This was done to simplify the interpretation of results.

The third criterion is the correlation between the daily time series. It is simply defined by the linear correlation coefficient.

The fourth criteria for the comparative analyses are intended to gain insight in comparing extreme values. They are the $99^{\text {th }}$ percentile of daily precipitation ( $\mathrm{mm} /$ day), the $99^{\text {th }}$ percentile of daily maximum temperature $\left({ }^{\circ} \mathrm{C}\right)$ and $5^{\text {th }}$ percentile of daily minimum temperature $\left({ }^{\circ} \mathrm{C}\right)$.

\subsection{Hydrological model}

The hydrological model used in this study is the HSAMI model (Fortin 2000; Minville et al. 2008). It is a lumped conceptual rainfall-runoff model developed and used operationally by Hydro-Québec for over 30 years. It is used to predict streamflow values on over 100 catchments in the province of Québec on an hourly and daily time scale. The HSAMI 
model has also been used extensively in streamflow prediction applications, climate change impact studies and rainfall-runoff modeling research projects (Arsenault and Brissette 2014b; Arsenault et al. 2013; Chen et al. 2011a, 2012; Chen et al. 2011b; Minville et al. 2008, 2009; Poulin et al. 2011). It simulates the main hydrological cycle processes such as vertical and horizontal water transfer, evapotranspiration, snowmelt and soil freezing. It has up to 23 parameters that must be calibrated: 10 for the various production function processes, 5 for the horizontal transfer through reservoir-type soil layers, 2 for evapotranspiration and 6 for snow-related processes. There are four interconnected reservoirs that contribute to the vertical water transfer balance: Snow on ground, surface runoff, saturated soil layer and unsaturated soil layer. The horizontal water transfer is based on two unit-hydrographs (one for surface runoff and one for underground runoff) and a linear reservoir. HSAMI requires spatially averaged minimum and maximum temperatures as well as rainfall and snowfall depths. The cloud cover fraction and snow on ground may also be used if they are available.

Because of the large number of catchments, an automatic optimization algorithm was chosen to perform the model calibrations. Arsenault et al. (2014) showed that the CMAES (Covariance Matrix Adaptation Evolution Strategy) (Hansen and Ostermeier 1996, 2001) algorithm was the optimal choice for calibrating the HSAMI model on 10 catchments, 8 of which 
were from the MOPEX database. Thus the CMAES optimization algorithm was used to perform the many calibrations in this project.

The calibration metric was computed on the odd years and crossvalidated on the even years, and vice-versa. This allowed taking into account any climatic trends (such as decadal or multi-decadal natural variability) or modifications in underlying data from the addition or removal of weather stations. However there is a drawback to this method: the model must be run for the entire period in order to select the odd years for calibration, thus doubling the computation requirements compared to traditional block-type calibration. Also, 10 calibrations were performed in the odd/even approach, as well as 10 other calibrations in the even/odd approach, for a total of 20 calibrations. Only the best parameter set was taken for each case. This reduces the likelihood of having the calibration algorithm not converge during the optimization process.

The Nash-Sutcliffe Efficiency (NSE) metric (Nash and Sutcliffe 1970) was used to compare hydrologic simulation performance levels. Other metrics could have been used, but the NSE is the most widely used metric and was the obvious choice for this study.

The NSE values were compared and the non-parametric Wilcoxon test was used to identify statistically significant differences in between results (Rakotomalala 2008). 
Furthermore, the precipitation and temperature datasets were then mixed and recombined to produce a total of 12 distinct datasets, and the calibration, validation and comparison aspects were also performed on the newly created datasets. Table 2 shows all of the resulting datasets used in this study.

TABLE 2. List of datasets used in this study and coverage periods.

\begin{tabular}{lll}
\hline \multicolumn{2}{c}{ Components } & Period \\
\cline { 1 - 2 } Temperatures & Precipitation & \\
\hline MOPEX & MOPEX & $1949-2003$ \\
\hline Santa-Clara & Santa-Clara & $1949-2003$ \\
\hline MOPEX & Santa-Clara & $1949-2003$ \\
\hline Santa-Clara & MOPEX & $1949-2003$ \\
\hline MOPEX & CPC & $1949-2003$ \\
\hline Santa-Clara & CPC & $1949-2003$ \\
\hline Daymet & Daymet & $1980-2003$ \\
\hline Daymet & MOPEX & $1980-2003$ \\
\hline Daymet & Santa-Clara & $1980-2003$ \\
\hline Daymet & CPC & $1980-2003$ \\
\hline MOPEX & Daymet & $1980-2003$ \\
\hline Santa-Clara & Daymet & $1980-2003$ \\
\hline
\end{tabular}

From Table 2, it is clear that the common period to all groups is 19802003. For this reason the entire study will be performed with these years to avoid any biases that could be caused by using different periods between the datasets. 


\section{Results}

\subsection{Temperature comparison}

\subsubsection{Mean daily temperature}

The results of the RMSE, bias and correlation coefficients between the mean daily temperature values of the MOPEX, Daymet and Santa Clara datasets are presented in Fig. 2. From Fig. 2A, it can be seen that comparatively to Daymet, the Santa-Clara mean daily temperatures deviate more from the MOPEX daily temperatures as approximately $71 \%$ of the catchments reflect a higher RMSE for the Santa-Clara dataset. However, the Santa-Clara and Daymet values are closer to one another than with MOPEX in the sense that RMSE values are smaller on $83 \%$ of the watersheds.

With respect to mean daily temperature, when compared to MOPEX, the Santa-Clara dataset has a median bias of $-0.2^{\circ} \mathrm{C}$, whereas Daymet shows a median bias equal to $-0.1^{\circ} \mathrm{C}$ (Fig. 2B). However, both datasets have a cold bias relatively to the MOPEX dataset on the majority of catchments (75\% and $65 \%$ of catchments respectively). As a general rule, SantaClara and Daymet temperatures are colder than MOPEX, but Daymet is globally warmer than Santa-Clara. 


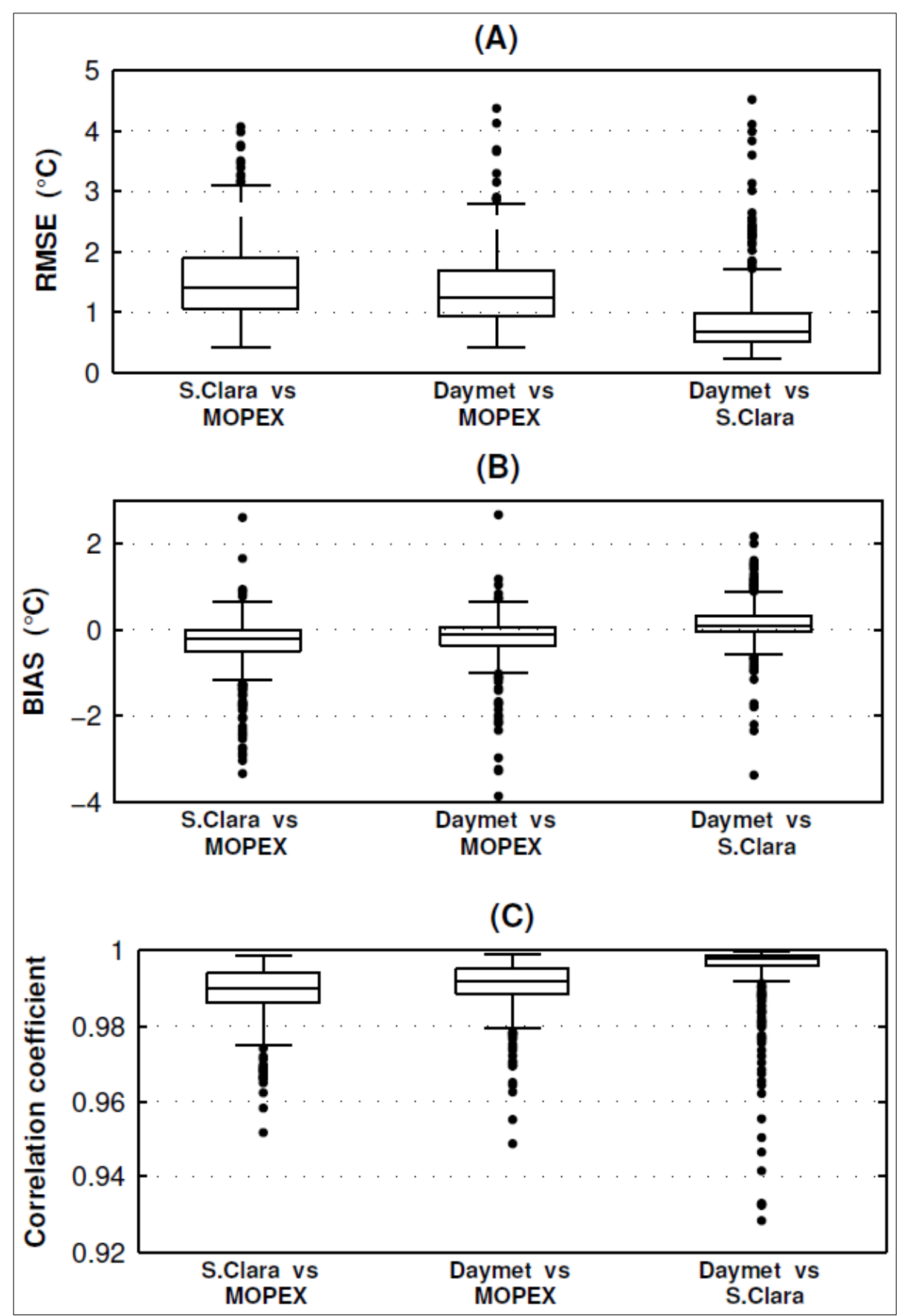

FIG. 2. RMSE (A), bias (B) and correlation coefficients (C) between the mean daily temperatures of the Santa-Clara, Daymet and MOPEX datasets. The lower and upper limits of each boxplot represent the 25th and 75 th percentiles, respectively. The middle line represents the median (50th percentile). The limit values of the whiskers correspond to $(u+2.7 \sigma)$ and $(\mathrm{u}-2.7 \sigma)$ where $\mathrm{u}=$ average of the plotted points and $\sigma=$ standard deviation. The outliers are points higher or smaller than the whiskers limits 
The three datasets are strongly correlated to one another with correlation coefficients between 0.93 and 1 for all basins (Fig. 2C).

There are, however, some statistically significant differences between the temperature datasets. The Wilcoxon test (95\% confidence interval) showed that the MOPEX dataset is different from its Santa-Clara and Daymet counterparts on $38 \%$ of the basins. Daymet and Santa-Clara are statistically different from one another in $36 \%$ of basins.

\subsubsection{Mean daily temperature by climatic zone}

The results of the RMSE between the mean daily temperature values of the MOPEX, Daymet and Santa-Clara datasets for each of the climatic zones are presented in Figs. 3A-3E. Results clearly show that RMSE values between Santa-Clara and MOPEX are larger than the ones between Daymet and MOPEX for all climatic zones with the exception of the Mediterranean catchments. Moreover, for the Santa-Clara dataset, the RMSE in semi-arid climate are relatively higher (median $=2.2^{\circ} \mathrm{C}$ ) but the RMSE in humid subtropical climate are lower $\left(\right.$ median $\left.=1.1^{\circ} \mathrm{C}\right)$. 


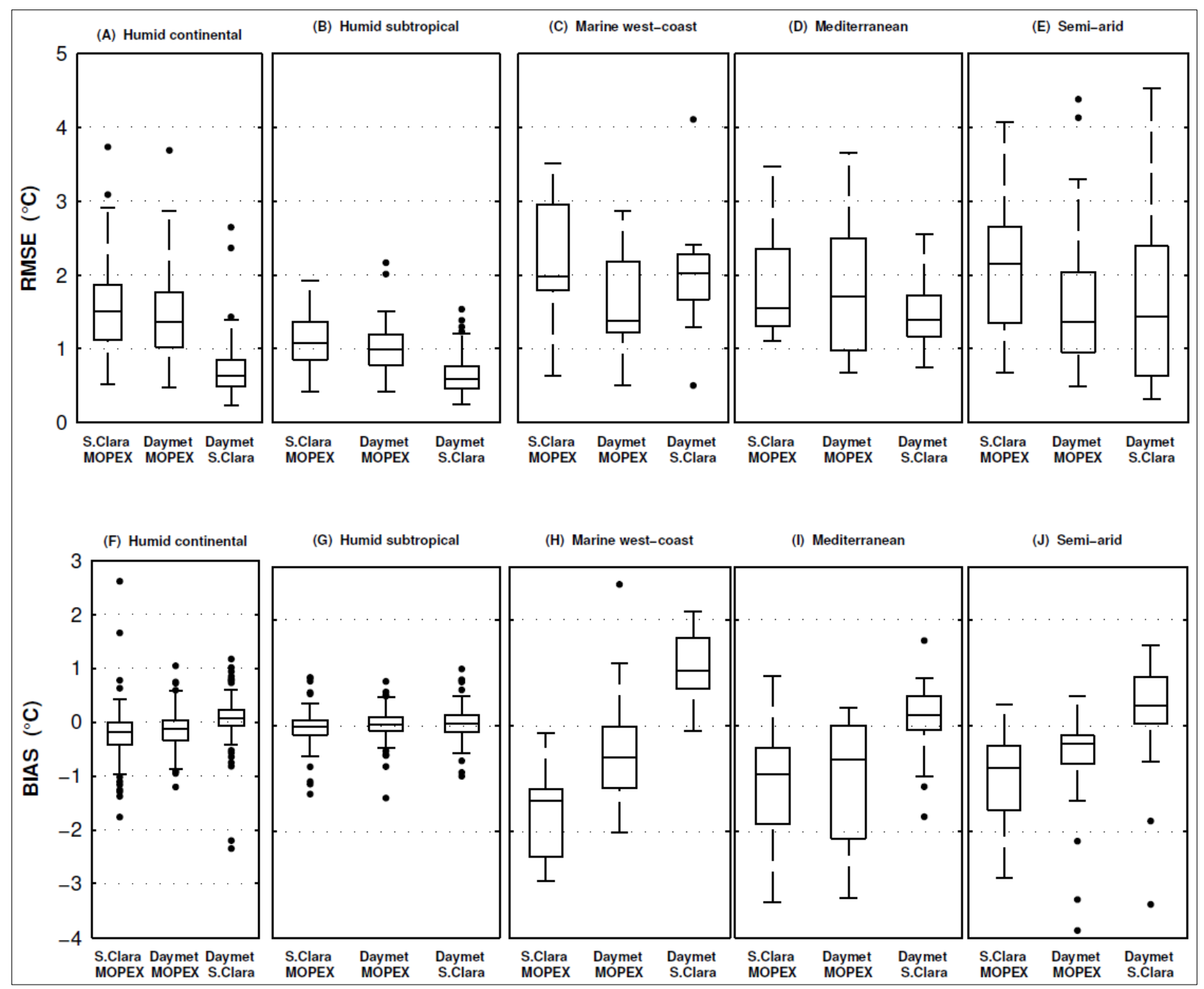

FIG. 3. Mean daily temperature RMSE and bias for the Santa-Clara, Daymet and MOPEX datasets for the 5 climate zones.

As for Daymet, the largest RMSE values were found in the Mediterranean region $\left(\right.$ median $=1.7^{\circ} \mathrm{C}$ ), and the lowest, in the humid subtropical climate (median $\left.=1.0^{\circ} \mathrm{C}\right)$. In all climatic zones, with the exception of the oceanic and semi-arid zones, Daymet and Santa-Clara temperatures are more similar to one another than to the MOPEX dataset. In the oceanic and semi-arid zones, Daymet values are closer to MOPEX than Santa-Clara. 
The results for the bias are presented in Figs. 3F-3J. The results show that in all the climatic zones, the Santa-Clara temperature biases relative to the MOPEX temperature are mainly cold (median bias $<0^{\circ} \mathrm{C}$ ). However, these biases are colder in the marine/west-coast climate region (median $=-1.4^{\circ} \mathrm{C}$ ) and approximately nil in the subtropical humid climate (median $=-0.01^{\circ} \mathrm{C}$ ). The Daymet biases (when compared to MOPEX) are mainly cold as well in all climate zones except for the humid subtropical climate where the median bias is also approximately nil $\left(\right.$ median $\left.=0.02^{\circ} \mathrm{C}\right)$. The Mediterranean climate is relatively colder with a median bias of $-0.6^{\circ} \mathrm{C}$. In all climate zones, the Daymet biases are mostly warmer than SantaClara, and particularly so in the oceanic climatic zone $($ mean bias $=$ $\left.1.03^{\circ} \mathrm{C}\right)$

Generally, the differences between the three datasets are smaller in the humid continental and subtropical humid climatic zones. The Wilcoxon test indicates that in those two climatic zones, the MOPEX dataset differs from the other two datasets in only $30 \%$ of the basins, compared to 66$100 \%$ in the other climatic zones.

\subsubsection{Mean seasonal temperatures}

Results are similar for seasonal temperatures and are not shown. RMSE values between mean seasonal temperatures are relatively small for both Santa-Clara and Daymet when compared to MOPEX. However, for all seasons, Santa-Clara displays larger RMSE values than Daymet when 
compared to MOPEX. Also, in both cases, the temperature RMSE values are generally higher in winter (median $\mathrm{RMSE}=0.3^{\circ} \mathrm{C}$ ) and lower in summer (median RMSE $=0.1^{\circ} \mathrm{C}$.

As expected, mean seasonal biases follow the cold biases of the daily mean temperature for both Daymet and Santa-Clara, and for all seasons. The coldest biases are experienced in winter (median $=-0.4^{\circ} \mathrm{C}$ for SantaClara and $-0.2^{\circ} \mathrm{C}$ for Daymet) and the least cold biases in the summer (median $=-0.06^{\circ} \mathrm{C}$ for Santa-Clara and $-0.01^{\circ} \mathrm{C}$ for Daymet). In all cases, biases related to the MOPEX seasonal temperatures are colder for the Santa-Clara dataset than for Daymet.

\subsubsection{Extreme temperatures: $99^{\text {th }}$ percentile of daily maximum temperatures and $1^{\text {st }}$ percentile of daily minimum temperatures}

The relative differences of temperature extremes for all three datasets are presented in Figure 4. For the daily maximum temperature (Fig. 4A) the median biases are relatively small in all cases. When compared to MOPEX, the $99^{\text {th }}$ percentiles of daily maximum temperatures of SantaClara have a warm bias on $57 \%$ of basins (median bias of $0.1^{\circ} \mathrm{C}$ ) whereas those of Daymet have a cold bias on $65 \%$ of basins (median of $-0.1^{\circ} \mathrm{C}$ ). This implies a cold bias for the $99^{\text {th }}$ percentiles of daily maximum 
temperatures of Daymet compared to their Santa-Clara counterparts on $74 \%$ of the basins (median of $-0.2^{\circ} \mathrm{C}$ ).

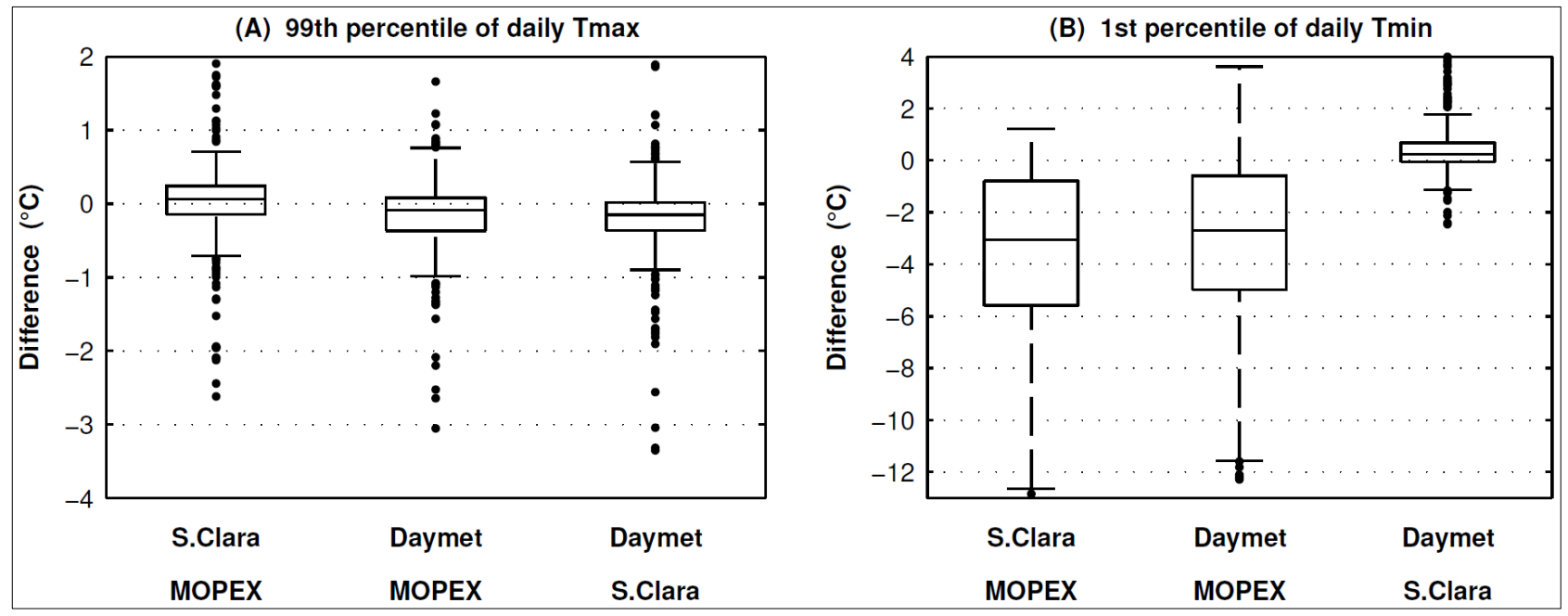

FIG. 4. Differences between extremes temperatures of the Santa-Clara, Daymet and MOPEX datasets.

Globally, the Santa-Clara dataset has the highest maximum temperatures, followed by MOPEX, with Daymet having the lowest maximum temperatures.

For the daily minimum temperatures (represented with the $1^{\text {st }}$ quantile), when compared to MOPEX, Santa-Clara and Daymet show differences between $-13.0^{\circ} \mathrm{C}$ and $4.0^{\circ} \mathrm{C}$. These biases are cold on respectively $91 \%$ and $88 \%$ of basins, with median biases of $-3.1^{\circ} \mathrm{C}$ and $-2.7^{\circ} \mathrm{C}$. In other words, MOPEX minimum extreme temperatures are much warmer whereas the Santa-Clara and Daymet datasets tend to produce lower minimum temperatures. Compared to Santa-Clara, Daymet minimum temperatures show biases between $-1^{\circ} \mathrm{C}$ and $1{ }^{\circ} \mathrm{C}$ on $80 \%$ of the basins. 


\subsection{Precipitation comparison}

\subsubsection{Daily precipitation}

The results of the daily precipitation RMSE, bias and correlation coefficients between the MOPEX, Santa-Clara, Daymet and CPC datasets are presented in Fig. 5. Results in Fig 5A show that the, Santa Clara precipitation is most similar to the MOPEX reference.. On $97 \%$ of the catchments, the daily precipitation RMSE of the Santa-Clara dataset is lower than that of the CPC dataset. In turn, the CPC daily precipitation RMSE is lower than for Daymet in $75 \%$ of the catchments.

With respect to the mean of all four datasets (used as a reference), mean daily precipitation of the MOPEX, Santa-Clara and CPC show dry biases on respectively $75 \%, 66 \%$ and $70 \%$ of basins with median values of $1.3 \%,-0.7 \%$ and $-1.2 \%$ (Fig $5 \mathrm{~B}$ ). At the other end of the spectrum, Daymet values have a wet bias on $86 \%$ of catchments with a median bias of 3.1\%. Overall, The CPC, Santa-Clara and Daymet datasets are wetter than the MOPEX dataset.

Correlation coefficients of daily precipitation between MOPEX and the other datasets display varying levels of correlation. Fig. 5C shows that the daily precipitation values are the most correlated to the MOPEX reference dataset. Furthermore, Daymet and CPC show very strong correlation, indicating that the precipitation is treated similarly in both interpolation methods. 


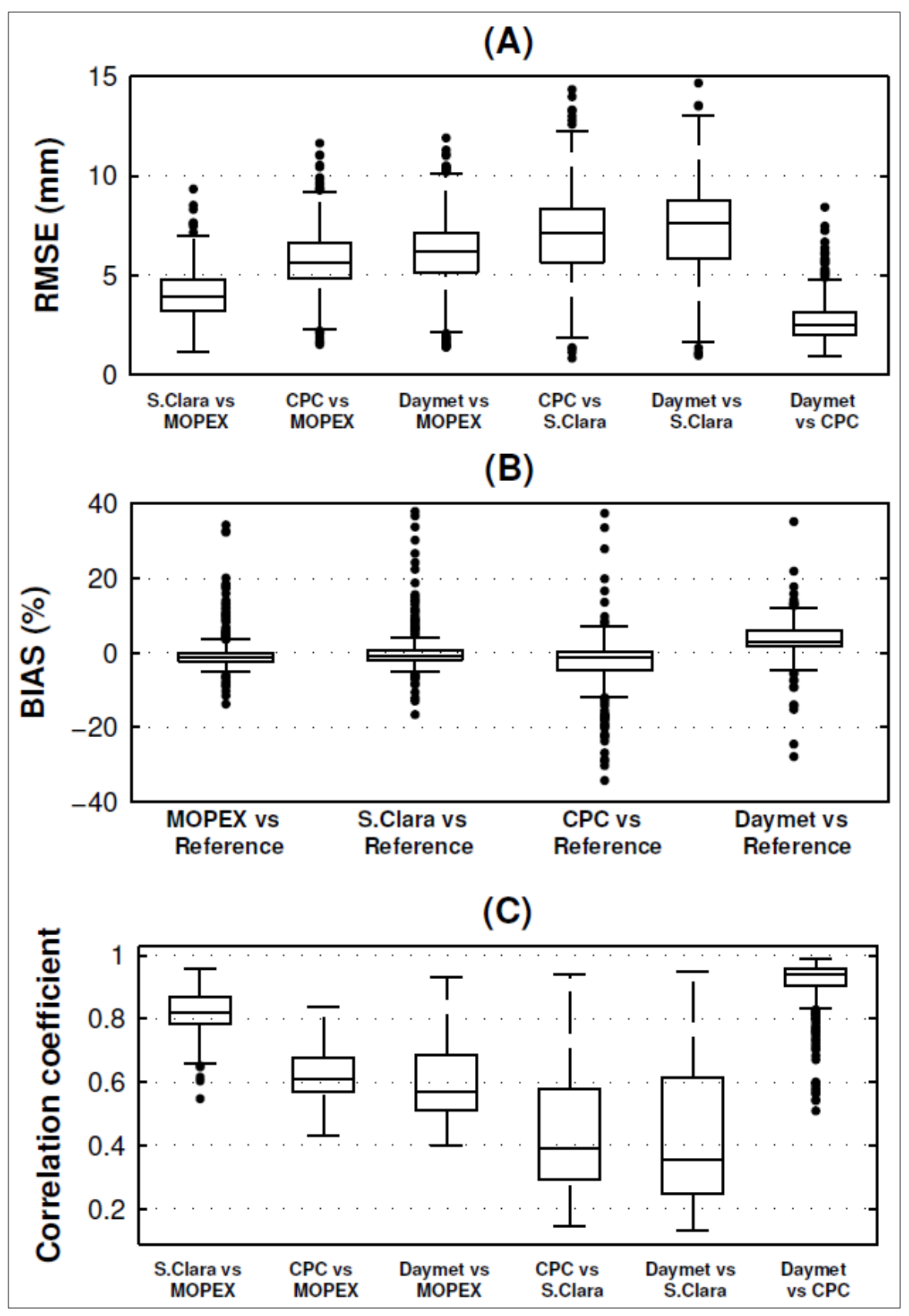

FIG. 5. RMSE (A), bias (B) and correlation coefficients (C) of the daily precipitation of the MOPEX, Santa-Clara, Daymet and CPC datasets.

\subsubsection{Daily precipitation by climatic zone}

The RMSE between daily precipitation datasets are presented by climatic zones in Figs. 6A-6E. In general the tendencies discussed in the preceding section mostly apply to all climate zones. In particular, in the 
humid continental and subtropical zones, Santa-Clara and MOPEX are closer to one another. All four datasets are in best agreement in the semi-arid climatic zone (median RMSE of $2.5 \mathrm{~mm}$ ).

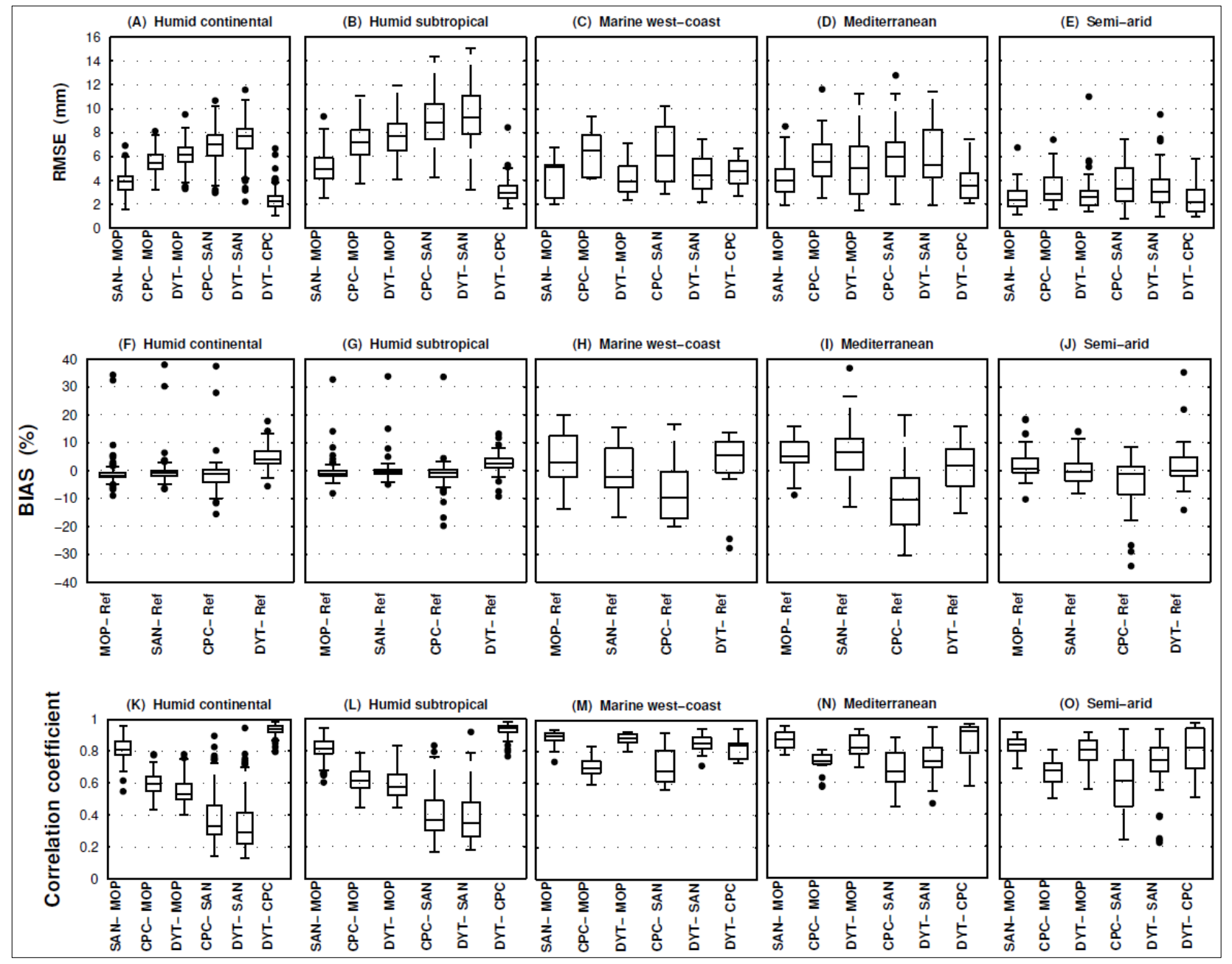

FIG. 6. Daily precipitation correlation coefficient (A-E), RMSE (F-J) and bias (K-O) for all the datasets for the 5 climate zones. (MOP = MOPEX; SAN = Santa-Clara; DYT = Daymet; Ref=Reference $($ mean of all four datasets)).

The biases of daily precipitation are presented in Figs. 6F-6J. As mentioned earlier, biases are compared against reference values computed as the mean of all four datasets. Biases are smaller in the 
humid continental and subtropical zones. In both of those zones, biases are mostly dry for MOPEX (median bias $=-1.8 \%$ and $-1.1 \%$ ), Santa-Clara $(-0.9 \%$ and $-0.5 \%)$ and $\mathrm{CPC}(-1.1 \%$ and $-0.8 \%)$. Conversely, Daymet has mostly humid biases for the same two climatic zones $(3.8 \%$ and $2.5 \%)$. For all other climatic zones, MOPEX is the most humid dataset and CPC is the driest.

Correlation coefficients of daily precipitation between all four datasets are presented in Figs 6K-6O. An analysis of the results reveals very similar conclusions to those of RMSE. This can easily be seen as Figs. $6 \mathrm{~K}-6 \mathrm{O}$ are practically mirror images of Figs. $6 \mathrm{~A}-6 \mathrm{E}$. All four datasets are in best agreement in the Oceanic and Mediterranean climatic zones (median correlation coefficient of 0.67 ). The correlation coefficients are lower than 0.5, especially between $\mathrm{CPC}$ and Santa-Clara, and between Daymet and Santa-Clara, in the humid continental and subtropical zones. In these two regions, Daymet and CPC correlate well, possibly because both use the NCDC weather stations network which is quite dense in the eastern United States. The Santa Clara database is built from a different weather stations network, and that may explain why it weakly correlates with Daymet and CPC. In the humid Continental and Subtropical regions, precipitation is unevenly distributed over the year and most rainfall occurs as convective storms in the summer because of the tropical atmospheric flow from the Gulf of Mexico. These local events may be differently represented in Santa Clara and Daymet (or CPC) 
because of the use of different weather stations networks, and lead to low correlation. Although in general Santa Clara is not well correlated with Daymet and CPC, the correlation coefficients in CPC and Santa-Clara, and in Daymet and Santa-Clara, are overall higher in the Oceanic and Mediterranean regions, where precipitation has a low spatial variability because it is influenced by the proximity to the Pacific Ocean.

\subsubsection{Total seasonal precipitation}

Trends for seasonal precipitation are similar to annual ones (results not shown). When compared to MOPEX, for all seasons, the smallest RMSE belongs to the Santa-Clara dataset followed by CPC and Daymet. CPC and Daymet are closest to one another. RMSE values for all databases are larger in the summer and lower in the winter. The median biases of total seasonal precipitation compared against reference values (the mean of all four datasets) are shown in Table 3.

TABLE 3. Median biases of total seasonal precipitation compared against the mean of all four datasets (\%)

\begin{tabular}{ccccc} 
& MOPEX & Santa Clara & CPC & Daymet \\
\hline Winter & $-0.7 \%$, & $-1.1 \%$ & $-2.1 \%$ & $4.1 \%$ \\
\hline Spring & $-1.6 \%$ & $-0.7 \%$ & $-2.6 \%$ & $5.1 \%$ \\
\hline Summer & $-1.9 \%$ & $-0.6 \%$ & $0.1 \%$ & $2.3 \%$ \\
\hline Fall & $-1.6 \%$, & $-1.0 \%$ & $-2.4 \%$ & $4.6 \%$ \\
\hline
\end{tabular}


Results indicate that biases are mostly dry in winter, spring and fall for MOPEX, Santa-Clara and CPC. In the summer, CPC biases are small and mostly humid whereas MOPEX and Santa-Clara datasets are dry. Daymet is the wettest dataset with wet biases for all seasons.

\subsubsection{Extreme precipitations: $99^{\text {th }}$ percentile of daily} precipitation distribution

The distributions of extreme precipitation biases between the four datasets are presented in Fig. 7.

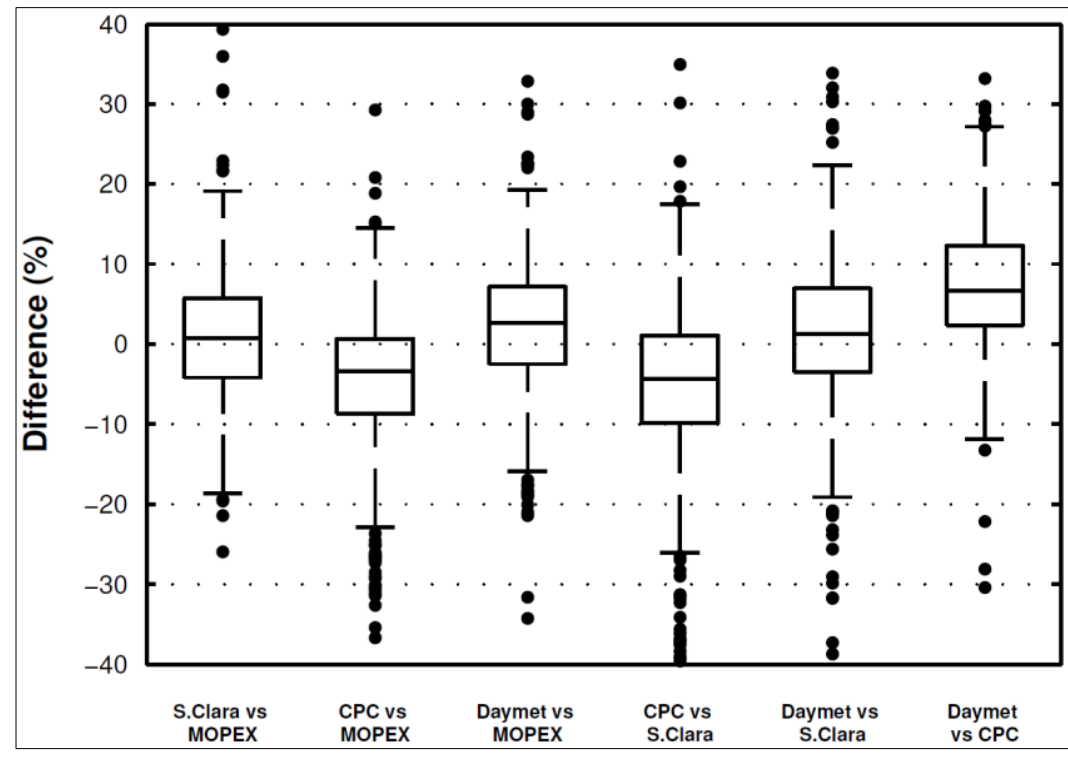

FIG. 7. Differences between the $99^{\text {th }}$ percentile of daily precipitation distribution of the MOPEX, Santa-Clara, CPC and Daymet datasets.

Results show that when compared to MOPEX, the biases of extreme precipitation for the Santa-Clara, CPC and Daymet datasets have median values respectively equal to $0.7 \%,-3.4 \%$ and $2.6 \%$. These biases are humid on respectively $55 \%, 28 \%$ and $64 \%$ of basins. This implies that 
extreme precipitations from the Santa-Clara and Daymet datasets are larger overall than those of the MOPEX dataset.

\subsection{Hydrological performance}

The performance of the HSAMI hydrological model is first assessed using the MOPEX database. Results are shown in Fig. 8 and indicate that the hydrology model performs reasonably well, with a NSE median value of 0.783 .

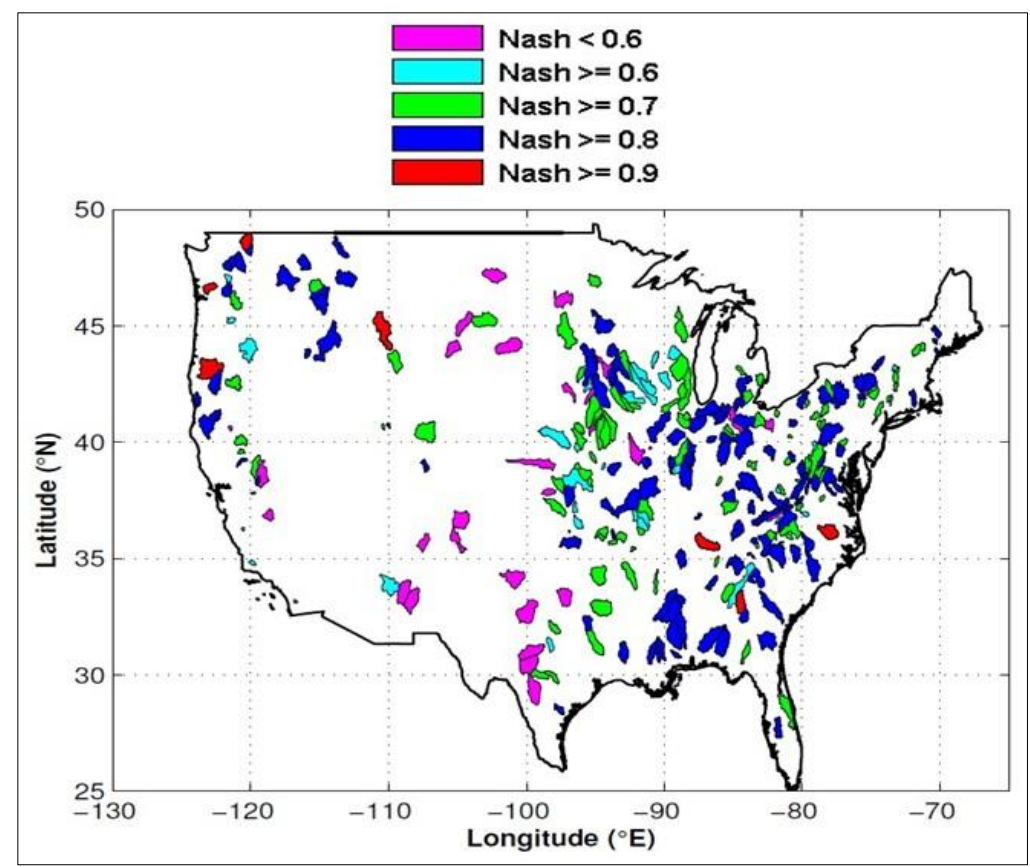

FIG. 8. Validation results (NSE) of the HSAMI hydrological model using the MOPEX database (Flow discharge, precipitation and temperature).

The model performs well over most of the United States with the exception of the semi-arid climate (see Fig. 1) where several catchments have a NSE value inferior to 0.6. This is not surprising considering that 
the hydrology model used in this study was developed for temperate climates and is not well adapted to the specific conditions of more arid landscapes. However, since the goal of this study is an inter-comparison of datasets, this relative lack of performance in semi-arid regions is of minimal concern.

The distribution of hydrological model performances using the various datasets is presented in Fig. 9.

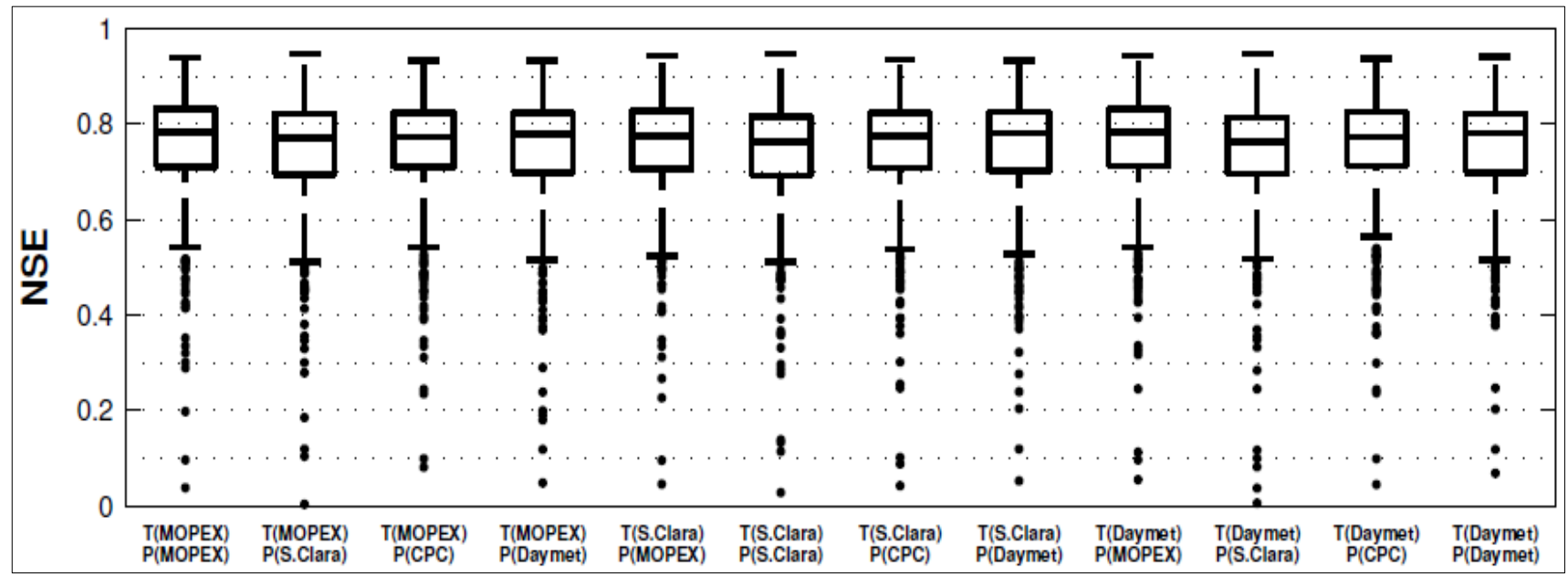

FIG. 9. Validation NSE distributions for the 12 climate datasets.

It is clear from that figure that the performance level is similar overall. Median validation NSE values from the MOPEX, Santa-Clara and Daymet datasets were found to be respectively equal to $0.783,0.762$ and 0.780 . For all hybrid combinations of precipitation and temperature data, the median NSE values were between 0.763 and 0.783. A comparison was made catchment-by-catchment to determine the frequency with which each climate combination shows superior performance. The results are shown in Table 4. 
TABLE 4. Frequency with which each climate combination shows superior performance.

\begin{tabular}{lccccr}
\cline { 2 - 5 } & \multicolumn{5}{c}{ PRECIPITATION (P) } \\
\cline { 1 - 5 } $\begin{array}{c}\text { TEMPEATURE } \\
(\mathbf{T})\end{array}$ & $\begin{array}{c}\text { MOPEX } \\
(\%)\end{array}$ & $\begin{array}{c}\text { Santa-Clara } \\
(\%)\end{array}$ & $\begin{array}{c}\text { CPC } \\
(\%)\end{array}$ & $\begin{array}{c}\text { Daymet } \\
(\%)\end{array}$ & Total (\%) \\
\hline MOPEX & 14.07 & 4.77 & 6.03 & 10.30 & $\mathbf{3 5 . 1 7}$ \\
\hline Santa-Clara & 7.79 & 7.79 & 8.04 & 11.81 & $\mathbf{3 5 . 4 3}$ \\
\hline Daymet & 5.28 & 8.04 & 6.53 & 9.55 & $\mathbf{2 9 . 4 0}$ \\
\hline Total (\%) & $\mathbf{2 7 . 1 4}$ & $\mathbf{2 0 . 6 0}$ & $\mathbf{2 0 . 6 0}$ & $\mathbf{3 1 . 6 6}$ & $\mathbf{1 0 0}$ \\
\hline
\end{tabular}

Table 4 indicates that all datasets perform at a very similar level. Still, it indicates that the $\mathrm{T}_{(\mathrm{MOPEX})}-\mathrm{P}_{(\mathrm{MOPEX})}$ dataset performs better on average, followed by $\mathrm{T}_{\text {(S.Clara) }}-\mathrm{P}_{\text {(Daymet) }}$.

A Wilcoxon test was performed between each of the groups in Fig. 9 to determine which ones were statistically different. Results reveal statistically significant differences between some combinations of temperature and precipitation datasets:

1- The combinations $\mathrm{T}_{\text {(MOPEX) }}-\mathrm{P}_{(\mathrm{MOPEX})}$ and $\mathrm{T}_{\text {(Daymet) }}-\mathrm{P}_{\text {(MOPEX) }}$ are statistically different from all combinations using Santa-Clara's precipitation $\left(\mathrm{T}_{(\text {MOPEX) }}-\mathrm{P}_{(\text {(S.Clara) }}, \mathrm{T}_{\text {(S.Clara) }}-\mathrm{P}_{(\text {S.Clara) }}\right.$ and $\left.\mathrm{T}_{(\text {Daymet })}-\mathrm{P}_{(\text {(S.Clara) }}\right)$.

2- The Santa-Clara dataset $\left(\mathrm{T}_{(\mathrm{S} . \text { Clara) }}-\mathrm{P}_{(\mathrm{S} . \text {.Clara })}\right)$ differs from any combination dataset obtained by substituting $\mathrm{P}_{\text {(S.Clara) with either }}$ $\mathrm{P}_{(\mathrm{MOPEX})}, \mathrm{P}_{(\mathrm{CPC})}$ or $\mathrm{P}_{(\text {Daymet })}$. 
3- The combination $\mathrm{T}_{\text {(S.Clara) }}-\mathrm{P}_{\text {(S.Clara) }}$ is different from any dataset containing Daymet precipitation.

These results unsurprisingly indicate that precipitation datasets are more critical than temperature datasets for hydrological modeling.

The performance of all 12 combination datasets was also analyzed with respect to seasonal discharge and annual maximum discharge. The results for seasonal values (not shown) are similar to those presented in Fig. 9. All datasets perform better in winter (median NSE values between 0.626 and 0.737 ) and spring (median NSE values between 0.716 and 0.759), but not as well in summer (median NSE values between 0.631 and 0.705) and fall (median NSE values between 0.546 and 0.694). The different seasonal performances may partly be due to the different seasonal biases of precipitation (as shown in Table 3). Furthermore, they may be caused by the different hydrological regimes that prevail and that vary from a season to another. For example, in spring, the streamflows are mainly influenced by snowmelt and are more easily simulated because they vary gradually. In summer, the streamflows are mainly influenced by rainfall which has high spatial and temporal variability, thus making modeling more challenging.

Further analyses based on catchment size and climate zone classifications were also performed. Following these tests, it was shown that basin size had no impact on the relative performances of the groups, 
while the climate dataset only played a role only on the Mediterranean climate basins. The NSE distributions for the 12 climate datasets on the Mediterranean climate catchments are presented in Fig. 10.

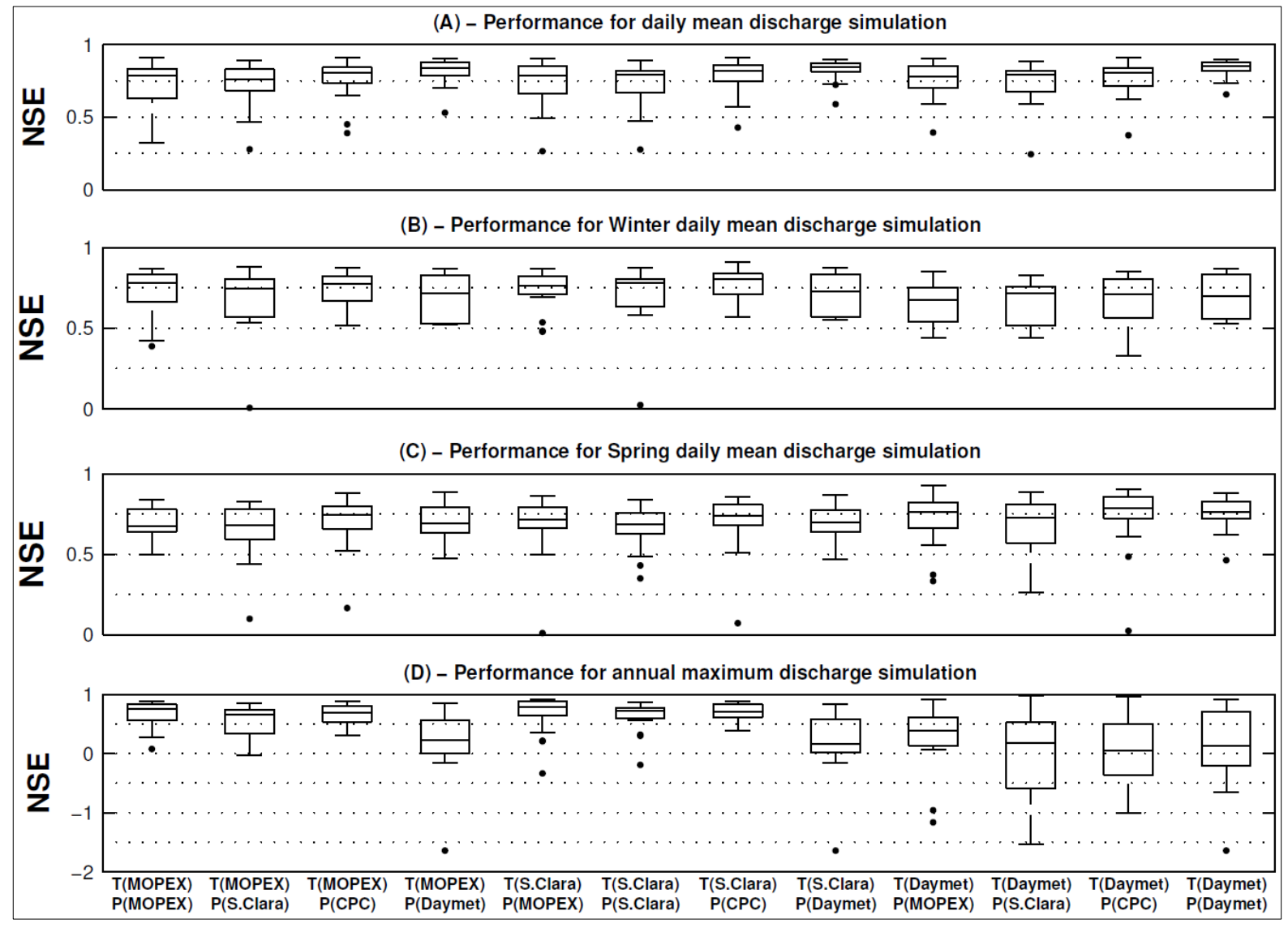

FIG. 10. Validation NSE distributions on the Mediterranean catchments for the 12 climate datasets. There are 24 catchments under a Mediterranean climate.

It can be seen in Fig. 10A that for the 24 Mediterranean climate catchments, using Daymet precipitation results in much better simulations, independently of the temperature datasets used. The spread is also smaller. The MOPEX precipitation is the least adequate for this climate zone resulting in a lower median performance value and a larger 
spread. It is not clear as to why this is the case. These catchments are located in mountainous regions, but so are the catchments from the west coast climate zone which do not exhibit a similar pattern.

At the seasonal scale, the only noticeable differences between the 12 datasets were all observed in the Mediterranean climatic zone, and only in winter and spring. In this climatic zone, the best spring and winter modeling results always used the $\mathrm{CPC}$ precipitation, independently of which temperature dataset was used (Figs. 10B and 10C).

\section{Discussion}

While weather station networks remain the most important source of information for hydrological modeling, their often low spatial resolution can sometimes lead to unrepresentative and poor model performance (Arsenault and Brissette 2014a). The need to improve this resolution has been the driving force behind gridded and interpolated climate datasets. However, such datasets have limitations with respect to hydrological modeling (Mizukami and Smith 2012; Muñoz et al. 2011).

Gridded datasets have the important advantage of having no missing data and the potential ability to generate valuable information in areas not densely covered by weather stations, especially when taking into account external variables such as elevation (Tapsoba et al. 2005). On the other hand, interpolating algorithms are limited in this potential ability, and "spreading" very sparse station data onto a fine grid may 
results in artifacts not anchored in any real physics. The uncertainties resulting from the interpolation algorithm manifest themselves in the sometimes large differences between the datasets. The variability in the contributing observational networks also plays a role in generating variability in the gridded datasets. These differences sometimes remain large even at the basin scale as seen in this study.

To shed light on these issues, fours interpolated datasets were compared in this study with an emphasis on hydrological modeling. By mixing the 4 precipitation and 3 temperature datasets, flow discharge was simulated on the 424 catchments of the MOPEX database using the HSAMI hydrology model, resulting in 12 flow discharge time series for each catchment. A common 24-year period (1980-2003) was used for all datasets.

Results indicate that there are differences, sometimes significant, between all four datasets. They all display biases when compared amongst themselves. There is a good agreement between datasets for mean daily temperatures, especially in the humid continental and subtropical climatic zones. For mean daily temperatures, there are two distinct grouping with MOPEX-Santa-Clara and CPC-Daymet being close to one another. The sheer number of climate stations and their attributes makes it all but impossible to find correlations between underlying observation climate data and the final gridded product. Moreover, most publicly available weather stations are used by all datasets (some use a 
subset of the entire set, while others used all available data). It is out of the scope of this paper to explain the differences between the gridded products; readers are encouraged to read (Duan et al. 2006; Higgins et al. 2000; Maurer et al. 2002; Thornton et al. 2012) for more details on each dataset. However, the differences between the gridded products may largely be attributable to the interpolation schemes which differ substantially from one dataset to another.

Despite the observed differences, the use of each dataset as the driving meteorological input to a lumped hydrological model led to equally good modeling results. Consequently, within the limits of this study, all datasets appear to be similar and equally good for hydrological studies.

The resolution of the gridded dataset and the complexity of the interpolation scheme do not appear to have any effect in the results. This is likely partly due to the fact that a lumped model was used in the assessment and that all grid points were averaged at the catchment scale, perhaps hiding some potential advantages of the higher-resolution dataset. It is possible that advantages of higher resolution grids could be uncovered using distributed models on the larger catchments. But this would be a time-consuming and computationally-intensive task, especially to set-up and calibrate distributed hydrological models on a large number of catchments. In this study 101760 (424 catchments x 12 hybrid datasets $\times 20$ odd/even year calibrations) individual model calibrations were performed. This would be a daunting task for a 
complex distributed hydrological model, even on a subset of the catchments used in this study.

In this work, precipitation and temperature datasets were mixed and matched to form 12 different combinations. No ill-effects were observed in doing so, presumably because precipitation and temperature datasets are usually interpolated independently. As such, there is likely little physical coherence between values of precipitation and temperature in interpolated datasets. This is an aspect that could be better investigated through a comparison against high-resolution climate model or reanalysis of data, where physical consistency between datasets should arguably be much better preserved.

Using statistics averaged over the 424 catchments, this study showed that all gridded datasets behaved similarly for hydrological modeling. However, this study could not evaluate the impact of network density even though it is one of the most interesting scientific problems. The MOPEX database contains catchment-averaged temperature and precipitation data. Information about the number of stations used to generate the catchment-averaged data (which would be needed to estimate network density for each catchment) is not present in the database. Only a rough density estimate can be calculated from the MOPEX dataset requirements, which state "desired" minimums of 1, 2, 3 6 and 12 stations for basins less than 1, 10, 100, 1000 and 10000 square miles respectively. Network density could also be estimated using 
the existing NCDC stations. However, since watersheds in the MOPEX database were contributed by many different parties, such an estimation would be error-prone since stations from the CPC cooperative network could also have been used in some catchment and not in some others. Questions related to network density, such as whether or not gridded datasets offer benefits in areas with poor station coverage (as opposed to densely-covered regions where all datasets are expected to converge) would be better tackled using a small subset of carefully chosen watersheds for which precipitation and temperature data would be recalculated using NCDC stations for example.

Also worth noting is that the results are mostly similar from one climate region to the next, except in the Mediterranean climate zone where some differences are visible. However we must take into account the number of catchments in each zone. There are 24 Mediterranean and 13 Marine/West-coast catchments, whereas there are 343 catchments in the humid regions. The comparison between these groups is illustrative at best since there are an insufficient number of catchments for proper statistical significance testing in the small groups.

An advantage of using gridded datasets is that they are much easier to use than station data. They have uniform coverage and no missing data. Catchment-averaging can be done using a simple arithmetic mean instead of using weight-based averaging as is commonly done, with weights constantly changing depending on which stations are reporting 
data on any given day. However, gridded datasets are not available in real-time, or near real-time like station data. As such they cannot be used in forecasting mode unless the interpolation is also done in near real-time. This is a process that is now done in-house by many water resources managers, but not yet available to the general public. It is however foreseeable that such data will be available in the near future. For example, such a product is currently in development by Environment Canada (Choi et al. 2013).

Finally this study opens the door to a more in-depth investigation of other gridded datasets. For example, more complex datasets such as PRISM (Daly et al. 1994; Daly et al. 1997) and even reanalysis datasets could be included in such a study. Reanalysis datasets offer the advantage of a much larger set of variables that could be useful for hydrological modeling.

\section{Conclusion}

This study compared four different interpolated precipitation and temperature datasets (MOPEX, Santa-Clara, Daymet and $\mathrm{CPC}$ ), the last three being interpolated on a regular grid. The comparison was based on basin-averaged data. Their performance in hydrological modeling over 424 catchments in the continental US was analyzed. The spatial heterogeneity of the catchments allowed comparing the HSAMI model performance relative to catchment size and climate attributes. 
The comparison was two-fold. First, the climate characteristics were compared to one another with various metrics, and the correlation coefficients, RMSE and bias were compared between the groups. It was shown that there are non-negligible biases between the interpolated datasets for many catchments. Second, each interpolated dataset was used as direct input to a specifically calibrated hydrological model. Although there are important differences between the various precipitation and temperature datasets, their hydrological performances in validation was not statistically different for most of the watersheds. It appears that there is no reason to favor one dataset versus another for lumped hydrological modeling, and that these datasets perform just as well as using the basin-averaged original station data.

\section{Acknowledgements}

This work was funded through a Natural Science and Engineering Research Council collaborative research grant (NSERC-CRD) with HydroQuébec, Rio-Tinto-Alcan, Ontario Power Generation and the Ouranos consortium on regional climatology and adaptation to climate change as industrial partners. These industrial research partners are greatly acknowledged for their direct and indirect contributions to this work. We also sincerely thank all the individuals and institutions that developed the datasets used in this work, and made them available to the scientific community. We hope that this work is a small contribution to their important effort. 


\section{REFERENCES}

Ali, M., S. Ye, H.-y. Li, M. Huang, L. R. Leung, A. Fiori, and M. Sivapalan, 2014: Regionalization of subsurface stormflow parameters of hydrologic models: Up-scaling from physically based numerical simulations at hillslope scale. Journal of Hydrology, 519, 683-698.

Arsenault, R., and F. Brissette, 2014a: Determining the optimal spatial distribution of weather station networks for hydrological modeling purposes using RCM datasets: An experimental approach. Journal of Hydrometeorology, 15, 517-526.

Arsenault, R., and F. P. Brissette, 2014b: Continuous streamflow prediction in ungauged basins: The effects of equifinality and parameter set selection on uncertainty in regionalization approaches. Water Resources Research, 50, 6135-6153.

Arsenault, R., A. Poulin, P. Côté, and F. Brissette, 2014: Comparison of Stochastic Optimization Algorithms in Hydrological Model Calibration. J. Hydrol., Eng, 19, 1374-1384.

Arsenault, R., F. Brissette, J.-S. Malo, M. Minville, and R. Leconte, 2013: Structural and non-structural climate change adaptation strategies for the Péribonka water resource system. Water resources management, 27, 2075-2087.

Baillargeon, S., J. Pouliot, L. Rivest, V. Fortin, and J. Fitzback, 2004: Interpolation statistique multivariable de données de précipitations dans un cadre de modélisation hydrologique. les actes du colloque national Géomatique 2004 de l'Association canadienne des sciences géomatiques.

Chen, D., L. Gong, C. Y. XU, and S. Halldin, 2007: A HIGHRESOLUTION, GRIDDED DATASET FOR MONTHLY TEMPERATURE NORMALS (1971-2000) IN SWEDEN. Geografiska Annaler: Series A, Physical Geography, 89, 249-261.

Chen, J., F. P. Brissette, and R. Leconte, 2011a: Uncertainty of downscaling method in quantifying the impact of climate change on hydrology. Journal of Hydrology, 401, 190-202.

— 2012: Downscaling of weather generator parameters to quantify hydrological impacts of climate change. Climate Research, 51, 185.

Chen, J., F. P. Brissette, A. Poulin, and R. Leconte, 2011b: Overall uncertainty study of the hydrological impacts of climate change for a Canadian watershed. Water Resources Research, 47. 
Choi, H., P. Rasmussen, and V. Fortin, 2013: Evaluation and Comparison of Historical Gridded Data Sets of Precipitation for Canada. AGU Fall Meeting Abstracts, 1481.

Cressman, G. P., 1959: An operational objective analysis system. Monthly Weather Review, 87, 367-374.

Daly, C., R. P. Neilson, and D. L. Phillips, 1994: A statistical-topographic model for mapping climatological precipitation over mountainous terrain. Journal of applied meteorology, 33, 140-158.

Daly, C., G. Taylor, and W. Gibson, 1997: The PRISM approach to mapping precipitation and temperature. Proc., 10th AMS Conf. on Applied Climatology, 20-23.

Dirks, K., J. Hay, C. Stow, and D. Harris, 1998: High-resolution studies of rainfall on Norfolk Island: Part II: Interpolation of rainfall data. Journal of Hydrology, 208, 187-193.

Duan, Q., and Coauthors, 2006: Model Parameter Estimation Experiment (MOPEX): An overview of science strategy and major results from the second and third workshops. Journal of Hydrology, 320, 3-17.

Elsner, M. M., S. Gangopadhyay, T. Pruitt, L. Brekke, N. Mizukami, and M. Clark, 2014: How does the Choice of Distributed Meteorological Data Affect Hydrologic Model Calibration and Streamflow Simulations? Journal of Hydrometeorology.

Fortin, V., 2000: Le modèle météo-apport HSAMI: historique, théorie et application. Institut de recherche d'Hydro-Québec, Varennes.

Gallo, K., and G. Xian, 2014: Application of spatially gridded temperature and land cover data sets for urban heat island analysis. Urban Climate.

Hansen, N., and A. Ostermeier, 1996: Adapting arbitrary normal mutation distributions in evolution strategies: The covariance matrix adaptation. Evolutionary Computation, 1996., Proceedings of IEEE International Conference on, IEEE, 312-317.

—, 2001: Completely derandomized self-adaptation in evolution strategies. Evolutionary computation, 9, 159-195.

Hartkamp, A. D., K. De Beurs, A. Stein, and J. W. White, 1999: Interpolation techniques for climate variables. CIMMYT Mexico, DF. 
Hasenauer, H., K. Merganicova, R. Petritsch, S. A. Pietsch, and P. E. Thornton, 2003: Validating daily climate interpolations over complex terrain in Austria. Agricultural and Forest Meteorology, 119, 87-107.

Higgins, R., W. Shi, E. Yarosh, and R. Joyce, 2000: Improved United States precipitation quality control system and analysis. NCEP/Climate Prediction Center Atlas, $\mathbf{7 .}$

Higgins, R. W., J. E. Janowiak, and Y.-P. Yao, 1996: A gridded hourly precipitation data base for the United States (1963-1993). US Department of Commerce, National Oceanic and Atmospheric Administration, National Weather Service.

Kottek, M., J. Grieser, C. Beck, B. Rudolf, and F. Rubel, 2006: World map of the Köppen-Geiger climate classification updated. Meteorologische Zeitschrift, 15, 259-263.

Mahdian, M., S. R. Bandarabady, R. Sokouti, and Y. N. Banis, 2009: Appraisal of the geostatistical methods to estimate monthly and annual temperature. Journal of Applied Sciences, 9, 128-134.

Maurer, E., A. Wood, J. Adam, D. Lettenmaier, and B. Nijssen, 2002: A Long-Term Hydrologically Based Dataset of Land Surface Fluxes and States for the Conterminous United States*. Journal of climate, 15, 32373251.

McEvoy, D. J., J. F. Mejia, and J. L. Huntington, 2014: Use of an Observation Network in the Great Basin to Evaluate Gridded Climate Data. Journal of Hydrometeorology, 15, 1913-1931.

Minville, M., F. Brissette, and R. Leconte, 2008: Uncertainty of the impact of climate change on the hydrology of a nordic watershed. Journal of hydrology, 358, 70-83.

- 2009: Impacts and uncertainty of climate change on water resource management of the Peribonka river system (Canada). Journal of Water Resources Planning and Management, 136, 376-385.

Mizukami, N., and M. B. Smith, 2012: Analysis of inconsistencies in multi-year gridded quantitative precipitation estimate over complex terrain and its impact on hydrologic modeling. Journal of Hydrology, 428, 129-141.

Muñoz, E., C. Álvarez, M. Billib, J. L. Arumí, and D. Rivera, 2011: Comparison of gridded and measured rainfall data for basin scale hydrological studies. Chilean Journal of Agricultural Research, 71, 459468. 
Nash, J., and J. Sutcliffe, 1970: River flow forecasting through conceptual models part I-A discussion of principles. Journal of hydrology, 10, 282-290.

Neiman, P. J., F. M. Ralph, B. J. Moore, and R. J. Zamora, 2014: The Regional Influence of an Intense Sierra Barrier Jet and Landfalling Atmospheric River on Orographic Precipitation in Northern California: A Case Study. Journal of Hydrometeorology.

Perry, M., and D. Hollis, 2005: The generation of monthly gridded datasets for a range of climatic variables over the UK. International Journal of Climatology, 25, 1041-1054.

Poulin, A., F. Brissette, R. Leconte, R. Arsenault, and J.-S. Malo, 2011: Uncertainty of hydrological modelling in climate change impact studies in a Canadian, snow-dominated river basin. Journal of hydrology, 409, 626636.

Rakotomalala, R., 2008: Comparaison de populations et tests non paramétriques. Université Lumière Lyon, 2.

Ruelland, D., S. Ardoin-Bardin, G. Billen, and E. Servat, 2008: Sensitivity of a lumped and semi-distributed hydrological model to several methods of rainfall interpolation on a large basin in West Africa. Journal of Hydrology, 361, 96-117.

Schaake, J., S. Cong, and Q. Duan, 2006: The US MOPEX data set. IAHS publication, 307, 9.

Schaake, J., Q. Duan, M. Smith, and V. Koren, 2000: Criteria to select basins for hydrologic model development and testing. Preprints, 15thConference on Hydrology, 10-14.

Shepard, D. S., 1984: Computer mapping: The SYMAP interpolation algorithm. Spatial Statistics and Models, Springer, 133-145.

Singh, R., S. Archfield, and T. Wagener, 2014: Identifying dominant controls on hydrologic parameter transfer from gauged to ungauged catchments-A comparative hydrology approach. Journal of Hydrology, 517, 985-996.

Skaugen, T., and J. Andersen, 2010: Simulated precipitation fields with variance-consistent interpolation. Hydrological sciences journal, 55, 676686.

Tapsoba, D., V. Fortin, F. Anctil, and M. Haché, 2005: Apport de la technique du krigeage avec dérive externe pour une cartographie 
raisonnée de l'équivalent en eau de la neige: Application aux bassins de la rivière Gatineau. Canadian journal of civil engineering, 32, 289-297.

Taylor, G., C. Daly, W. Gibson, and J. Sibul-Weisberg, 1997: Digital and map products produced using PRISM. Proc., 10th AMS Conf. on Applied Climatology, Amer. Meteorological Soc., Reno, NV, Oct, 20-24.

Thornton, P., M. Thornton, B. Mayer, N. Wilhelmi, Y. Wei, and R. Cook, 2012: Daymet: Daily surface weather on a $1 \mathrm{~km}$ grid for North America, 1980-2008. Oak Ridge National Laboratory Distributed Active Archive Center, Oak Ridge, T, N. doi, 10.

Thornton, P. E., S. W. Running, and M. A. White, 1997: Generating surfaces of daily meteorological variables over large regions of complex terrain. Journal of Hydrology, 190, 214-251.

Tozer, C., A. Kiem, and D. Verdon-Kidd, 2012: On the uncertainties associated with using gridded rainfall data as a proxy for observed. Hydrology and Earth System Sciences, 16, 1481-1499.

Widmann, M., and C. S. Bretherton, 2000: Validation of mesoscale precipitation in the NCEP reanalysis using a new gridcell dataset for the northwestern United States. Journal of Climate, 13, 1936-1950.

Ye, S., and Coauthors, 2014: Regionalization of subsurface stormflow parameters of hydrologic models: Derivation from regional analysis of streamflow recession curves. Journal of Hydrology, 519, 670-682.

Zurita-Milla, R., H. Mehdipoor, S. Batarseh, T. Ault, and M. D. Schwartz, 2014: On the use of gridded daily temperature data to calculate the extended spring indices phenological models. EGU General Assembly Conference Abstracts, 13427. 